\title{
Unconsciousness at Emergency as a Manifestation of Hashimoto’ s Encephalopathy
}

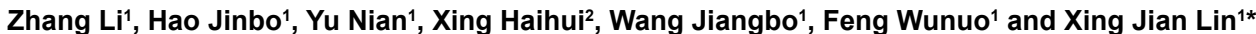

${ }^{1}$ Nanjing Medical University, Affiliated Nanjing Brain Hospital, Department of Neurology, China

${ }^{2}$ Nanjing Gaochun Chinese Medicine Hospital, Department of Neurology, China

\begin{abstract}
Unconsciousness is a common symptom of the emergency cases with various and complicated causes. Now we presented 4 patients with the disturbance of consciousness as a clinical manifestation of Hashimoto's encephalopathy (HE). All the four patients were suffered from different degrees of disturbance of consciousness at the emergency department and subsequently were diagnosed with HE at in-patient department. Finally, three patients of them got satisfactory prognosis and one patient died.
\end{abstract}

Keywords: Hashimoto encephalopathy; Unconsciousness; Steroidresponsive encephalopathy associated with autoimmune thyroiditis

\section{Introduction}

Hashimoto encephalopathy (HE) was first described in 1966 by Brain et al. [1]. The clinical features of this disorder included strokelike episodes, transient aphasia, ataxia, tremor, gait disturbances, nystagmus, headache, seizure, myoclonus, confusion, cognitive impairment, visual hallucinations, opsoclonus and behavioral disorder [2,3]. There are three distinct subtypes of HE described: 1) acute onset, with seizures and stroke-like episodes, often with a fluctuation course; 2) insidious onset, with progressive dementia and behavioral disturbance [4]; 3) relapsing-remitting manner of the cognitive deterioration and psychiatric illness [5].

\section{Case report}

All of the four patients were mainly manifesting unconsciousness when they were sent to the emergency department of our hospital from January 2010 to December 2012.

Case A: A 59 years old female presented insidious abnormal action such as difficulties in finding words, remembering recent events, and putting on quilt and trousers as coats sometimes for 2 months and was diagnosed with hyperthyroidism for 1 month in other hospital. The patient was lethargy at our emergency department. The patient's random blood glucose was $10.2 \mathrm{mmol} / \mathrm{L}$, and his blood ammonia was $40 \mu \mathrm{mol} / \mathrm{L}$ within normal limits. Dexamethasone was given $10 \mathrm{mg} /$ day from the second day. Thus the patient became more conscious in the third day yet with limb weakness. After the dexamethasone therapy of her inpatient care (7 days), she was discharged and prescribed with prednisone $20 \mathrm{mg} /$ day. This patient was followed for 6 months with clear consciousness and normal muscle force. Statistic result of the patient is shown in the Table 1 and Figure 1A.

Case B: A 19 years old female presented with sudden onset unconsciousness for one day with preceding history of dysphoretic, panic and querulous on the morning and seemed like normal at night. Her symptoms continued for one week. Four years ago, the patient had generalized tonic-clonic seizure transiently and was diagnosed with viral encephalitis at that time in the local hospital (lack of the detailed medical history). Then she took sodium valproate for 2 years without epileptic attack. The anti-epileptic drug has been withdrawn in the recent 2 years with normal EEG. She manifested delusion and delirium mood disturbance at emergency. The first day at in-patient department she fell down and had generalized tonic-clonic seizure for nearly 20 seconds. She still showed psychiatric symptom in next few days after oral anti-epileptic drug. The primary suspect of central nervous system infection was based on the negativity of herpes simplex virus in serum and cerebrospinal fluid (CSF) test, which showed normal intracranial pressure, normal CSF cell counts, and normal protein level. Therefore she was diagnosed with viral encephalitis initially. After the test of thyroid hormones, TPO-Ab and TG-Ab, we prescribed her methylprednisolone $500 \mathrm{mg} /$ day for 3 days, and gradually decreased to prednisone $20 \mathrm{mg} /$ day. She turned to be conscious after the steroid drug used, but she still had some symptom such as a little suspicious and querulous when discharged from hospital. One month later, she became better. Statistic result of the patient is shown in the table 1 and figure 1B.

Case C: A 46 years old female presented with insidious walking instability, lacking strength, fearing cold and increasing sleep for four months and was diagnosed with hypothyroidism 2 months ago. The condition did not get remission after taking Euthyrox and new symptoms such as blurred vision, limb numbness and difficulty in finding words were observed before hospital admission. She fell down and had tachypnea and aphasia one day before. The patient was observed light coma at emergency with random blood glucose $7.2 \mathrm{mmol} / \mathrm{L}$, blood ammonia $28 \mu \mathrm{mol} / \mathrm{L}$ (within normal limits). In the fourth day, she turned coma with methyl prednisolone therapy, and died at the eighth day because of respiratory failure. Statistic result of the patient is shown in the table 1 and figure $1 \mathrm{C}$.

Case D: A 43 years old male presented with dizziness, lacking strength, walking instability and intermittent hallucination for one and half years, and had generalized tonic-clonic seizure for 14 months.

*Corresponding author: Xing-Jian Lin, MD, Department of Neurology, Nanjing Brain Hospital, Nanjing Medical University, 264 Guangzhou Road, Nanjing, 210029 Jiangsu, China, Tel: 0086-2582296263; Fax: 0086-2583712308; E-mail: linppmm@126.com

Received December 05, 2013; Accepted February 10, 2014; Published February 17,2014

Citation: Li Z, Jinbo H, Nian Y, Haihui X, Jiangbo W, et al. (2014) Unconsciousness at Emergency as a Manifestation of Hashimoto's Encephalopathy. Bioenergetics 3 : 112. doi: $10.4172 / 2167-7662.1000112$

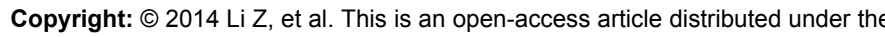
terms of the Creative Commons Attribution License, which permits unrestricted use, distribution, and reproduction in any medium, provided the original author and source are credited. 
Citation: Li Z, Jinbo H, Nian Y, Haihui X, Jiangbo W, et al. (2014) Unconsciousness at Emergency as a Manifestation of Hashimoto's Encephalopathy. Bioenergetics 3: 112. doi:10.4172/2167-7662.1000112

Page 2 of 3

\begin{tabular}{|c|c|c|c|c|}
\hline & A & B & C & D \\
\hline \multirow[t]{3}{*}{$\begin{array}{l}\text { History of past } \\
\text { illness }\end{array}$} & 1.hypertension 4 years & $\begin{array}{l}\text { symptomatic epilepsy } 4 \\
\text { years drug withdrawal } 2 \\
\text { years }\end{array}$ & 1. temporal lobe glioma exairesis four 4 ago & $\begin{array}{l}\text { 1.facial neuritis } 4 \text { years } \\
\text { 2.hypothyroidism over } 1 \text { year }\end{array}$ \\
\hline & $\begin{array}{l}\text { 2.type diabetes mellitus } 8 \\
\text { years }\end{array}$ & & 2.hypothyroidism 2 months & \\
\hline & 3.hyperthyroidism 1 month & & & \\
\hline Head CT & lacunar infarction & normal & multiple low signal & normal \\
\hline GCS & 8 & 11 & 6 & 6 \\
\hline \multirow[t]{2}{*}{ Head MRI } & $\begin{array}{l}\text { lacunar infarction and mild } \\
\text { cerebral atrophy }\end{array}$ & MRI: normal & $\begin{array}{l}\text { multiple hyper-signal of brainstem and cerebral } \\
\text { white matter on T2 weighted imaging with on } \\
\text { unusual enhancement }\end{array}$ & $\begin{array}{l}\text { hyper-signal of cerebral white } \\
\text { matter on } T 2 \text { weighted imaging }\end{array}$ \\
\hline & & $\begin{array}{l}\text { MRS: both hippocampi } \\
\text { abnormal especially the left }\end{array}$ & & \\
\hline EEG & generalized slowing of waves & $\begin{array}{l}\text { frontal and temporal region } \\
\text { slow wave }\end{array}$ & generalized slowing of waves & $\begin{array}{l}\text { frontal and temporal intermittent } \\
\text { rhythmic delta activity }\end{array}$ \\
\hline $\begin{array}{l}\mathrm{T} 3(1.49- \\
2.60 \mathrm{nmol} / \mathrm{L})\end{array}$ & 0.75 & 1.48 & 1.39 & 1.55 \\
\hline $\begin{array}{l}\text { FT3(4.26- } \\
8.10 \mathrm{pmol} / \mathrm{L})\end{array}$ & 2.39 & 5.86 & 3.55 & 4.96 \\
\hline $\begin{array}{l}\text { T4(71.2- } \\
\text { 141.0nmol/L) }\end{array}$ & 67.6 & 56.32 & 96.5 & 52.5 \\
\hline $\begin{array}{l}\text { FT4(10.0- } \\
\text { 28.2pmol/L) }\end{array}$ & 11.8 & 12.3 & 17.4 & 8 \\
\hline $\begin{array}{l}\text { TSH(0.46- } \\
\text { 4.68Miu/L) }\end{array}$ & 2.13 & 4.58 & 0.27 & 9.02 \\
\hline $\begin{array}{l}\text { TPO-Ab }(<34.01 \mathrm{U} / \\
\mathrm{ml})\end{array}$ & $>600.0$ & 58.1 & 489.7 & 520.8 \\
\hline $\begin{array}{l}\text { TG-Ab }(<115.0 \mathrm{IU} / \\
\mathrm{ml})\end{array}$ & 195.81 & 582.6 & 164.5 & 680 \\
\hline
\end{tabular}

Table 1: Clinical test results of 4 Hashimoto's Encephalopathy patients.

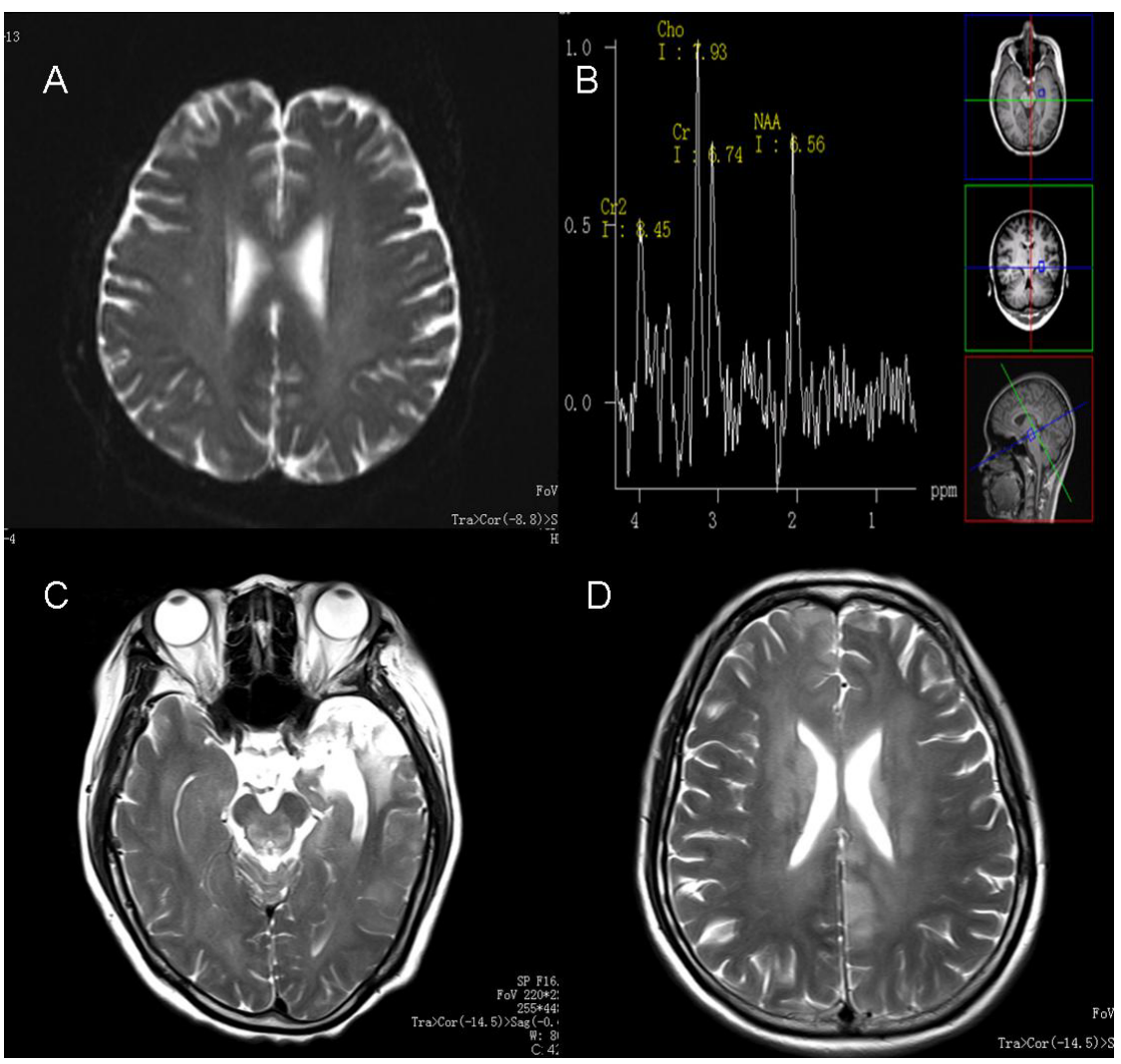

Figure 1: Brain MRI of the 4 cases. MRS of case B reveals both hippocampi especially the left decrease in NAA as well as elevations in Cr and Cho, NAA $(\mathrm{Cr}+\mathrm{Cho})<0.71$. In this spectrum, NAA stands for $\mathrm{N}$-acetylapartate(2.0 ppm), Cho for choline(3.2 ppm), Cr for creatine(3.0 ppm). 
Then he was diagnosed with viral encephalitis with CSF indicating mild infections of the central nervous system. The patient was detected as hypothyroidism and began to take Euthyrox from that time and got recovery after steroid drug therapy quickly. The headache, dysarthria and seizure attack of the patient were also improved by the steroid hormonal therapy. We diagnosed him HE with his CSF showed a little higher cell count and protein level and the test of thyroid hormones and TPO-Ab and TG-Ab, and then we gave him methyl prednisolone $1.0 \mathrm{~g} /$ day for 5 days and gradually decreased with prednisone $60 \mathrm{mg} /$ day. He turned conscious and spoke clearly in the third day after steroid hormonal therapy. We gave him azathioprine as immunosuppressive drugs, and he had less recurrence at clinical follow-up. Statistic result of the patient is shown in the table 1 and figure 1D.

\section{Discussion}

Holanda et al. [2] reviewed 130 patients from 52 studies showed that $53 \%$ patients had behavioral disorder, $65 \%$ patients had cognitive impairment, $32 \%$ patients had confusion, $27 \%$ patients had psychosis, and $7 \%$ patients had difficulty finding words. It is common for HE patients with disorders above, but we should pay attention to the patients with disorders of consciousness at emergency. This encephalopathy should be carefully diagnosed with Alzheimer's disease, Cerebrovascular accidents (stroke), Creutzfeldt-Jakob disease (CJD) and viral encephalitis particularly.

The exact pathogenesis of HE is unknown yet. It is reported to be an autoimmune encephalopathy because of its higher prevalence in females, fluctuating course, associating with other autoimmune disorders and improvement with steroid therapy. In our present report, three of four patients were female, and case D patient had relapsingremitting headache, dysarthria and epileptic attack. Especially, it was obvious that three patients were sensitive to steroid therapy. It is associated with TPO-Ab and TG-Ab in most articles [6], but Blanhin $S$ et al. [7] reported that TPO-Ab rather than TG-Ab in the CSF or serum could contribute to the disease itself by interacting with central nervous system tissue. But the precise role of antithyroid antibodies is unclear; some scientists have attempted to investigated the role of common antigens against thyroid and brain tissues, such as antigen amino terminal enolase, which may explain the pathophysiology and the diagnosis of the disease [8].

In review, $71.1 \%$ patients had the examination of CSF, which showed mild and nonspecific inflammatory state [2]. The most characteristic findings were the presence of TPO-Ab and TG-Ab and a high CSF protein concentration, which should reinforce the diagnosis.

The EEG had no specific findings of HE patients. The most common changes found were a widespread slowing of waves and frontal intermittent rhythmic delta activity. The degrees of slowness of the waves were related to the clinical severity of the encephalopathy. In more than half of $\mathrm{HE}$ patients, the most frequent finding of the MRI was hyper-signal on T2, which may present an edema or brain inflammation, and may be reversible after treatment with corticosteroids. This phenomenon is nonspecific and can be found in other causes of encephalopathy. The results of the examinations such as magnetic resonance angiography and SPECT have contributed little to the diagnosis [9].

In most patients there were complete remission of symptoms, however, there may be a form of partial remission, with persistence of neurological and imaging changes, and even death from complications of disease [10]. One of our patients died because of the complication for delay in treatment.

Treatment of HE can be based on the use of corticosteroids, such as IV methyl prednisolone (0.5-1.0 g per day) for 3 to 5 days, with oral prednisone at a high initial dose $(1-2 \mathrm{mg} / \mathrm{Kg}$ per day), followed by gradual reduction which is based on clinical improvement. We use azathioprine as immunosuppressive drugs in relapsing-remitting patients, while in cases $\mathrm{D}$, relapses can occur even after a significant improvement in symptoms or during the reduction in corticosteroid therapy [11].

It must be taken into account that when the patients had unconsciousness at emergency room, including not only cerebrovascular accidents, cardiopathy paroxysm, diabetes mellitus ketoacidosis, hepatic encephalopathy, hypoglycemic coma, hyponatremia, toxicosis and psychosis, but also other rare diseases when the examination doesn't fit the clinical feature.

Immediate and adequate therapy contributes significantly to a reduction in the high morbidity and mortality rates. In the patients with unconsciousness of unknown reasons, we must take HE into account as it is easy to diagnose and treat.

\section{Disclosure/Conflict of Interest}

None of the authors has any potential financial conflict of interest related to this manuscript.

\section{Acknowledgments}

This work was supported by grants from the Nanjing Medical Scientific and Technique Foundation of Jiangsu province, China (QRX11119).

\section{References}

1. Brain L, Jellineck EH, Ball K (1966) Hashimoto's disease and encephalopathy Lancet 2: 512-514.

2. de Holanda NC, de Lima DD, Cavalcanti TB, Lucena CS, Bandeira F (2011) Hashimoto's encephalopathy: systematic review of the literature and an additional case. J Neuropsychiatry Clin Neurosic 23: 384-390.

3. Salazar R, Mehta C, Zaher N, Miller D (2012) Opsoclonus as a manifestation of Hashimoto's encephalopathy. J Clin Neurosci 19: 1465-1466.

4. Chen HC, Marsharani U (2000) Hashimoto's encephalopathy. J South Med 93: 504-506.

5. Watemberg N, Greenstein D, Levine A (2006) Encephalopathy associated with Hashimoto thyroiditis: pediatric perspective. J Child Neurol 21: 1-5.

6. Oide T, Tokuda T, Yazaki M, Watarai M, Mitsuhashi S, et al. (2004) Antineuronal antoantibody in Hashimoto's encephalopathy: neuropathological, immunohistochemical, and biochemical analysis of two patients. J Neurol Sci 15: 7-12.

7. Blanchin S, Coffin C, Viader F, Ruf J, Carayon P, et al. (2007) Antithyroperoxidase antibodies from patients with Hashimoto's encephalopathy bind to cerebellar astrocytes. J Neuro immunol 192: 13-20.

8. Yoneda M, Fujii A, Ito A, Yokoyama H, Nakagawa H, et al. (2007) High prevalence of serum autoantibodies against the amino terminal of alphaenolase in Hashimoto's encephalopathy. J Neurommunol 185: 195-200.

9. Tamagno G, Celik Y, Simo R, Marcel D, Kazumi K, et al. (2010) Encephalopathy associated with autoimmune thyroid disease in patients with Graves' disease: clinical manifestations, follow-up, and outcomes. BMC Neurol 10: 1-8.

10. Tamagno G, Federspil G, Murialdo G (2006) Clinical and diagnostic aspects of encephalopathy associated with autoimmune thyroid disease (or Hashimoto's encephalopathy). Intern Emerg Med1: 15-23.

11. Katoh N, Yoshida T, Shimojima Y, Gono T, Matsuda M, et al. (2007) An 85-year-old case with Hashimoto's encephalopathy, showing spontaneous complete remission. Intern Med 46: 1613-1616. 